\title{
Experimental Evaluation of Methane Fuel Reformation Feasibility
}

\author{
C.M. Roseberry*, J.M. Meyers*, F.K. Lu ${ }^{\dagger}$ and D.R. Wilson ${ }^{\ddagger}$ \\ University of Texas at Arlington, Arlington, TX 76019 \\ Y.M. Lee ${ }^{\S}$ \\ MSE Inc., Butte, MT 59702 \\ and \\ P.A. Czysz \\ Hypertech Concepts, St. Louis, MO 63141
}

\begin{abstract}
Results of a preliminary experimental study to investigate the feasibility of reformation of hydrocarbon fuels into hydrogen and carbon by high-power, electric arc pyrolysis are presented. The goal is to obtain the high energy density of gaseous hydrogen fuel for combustion while still achieving the volumetric efficiency of much denser hydrocarbon fuels. A $1.6 \mathrm{MW}$ arc heater was modified to run on gaseous hydrocarbons, and a diagnostic chamber was developed to provide quantitative measurements of the products of pyrolysis. An electrical fault in the 1.6 MW power supply occurred early in the test program, thus the experimental data were obtained by using a commercial plasma cutting torch that was modified to run on methane. Preliminary results showed significant carbon deposition on the cold trap and identification of gaseous hydrogen via emission spectroscopy.
\end{abstract}

\section{INTRODUCTION}

Hydrogen is the fuel of choice for long-range hypersonic flight vehicles from the standpoint of enthalpy of reaction. However, the extremely low density of hydrogen results in excessive tankage, thereby causing adverse effects on vehicle size and weight. Hydrocarbon fuels do not have the enthalpy of reaction of hydrogen, but their higher density drastically reduces fuel tank volume (Fig. 1). A novel solution to this problem was proposed in the Russian AJAX hypersonic flight vehicle design that involved highcurrent pyrolytic reformation of hydrocarbon fuels such as methane into hydrogen and carbon

\footnotetext{
*Graduate Research Associate, Member AIAA.

${ }^{\dagger}$ Professor of Mechanical and Aerospace Engineering and Director, Aerodynamics Research Center, Assoc. Fellow AIAA.

*Professor of Mechanical and Aerospace Engineering, Assoc. Fellow AIAA.

${ }^{\S}$ Staff Engineer/Program Manager, Senior Member AIAA.

"President, Assoc. Fellow AIAA.

Copyright (C) 2003 by the American Institute of

Aeronautics and Astronautics, Inc. All rights reserved.
}

during flight. ${ }^{1}$

The electrical energy required for the arc heater would be obtained by tapping a part of the output from the MHD generator used in the combustion chamber kinetic energy bypass system. Thus, the high energy density of hydrogen would be available for combustion while still achieving the volumetric efficiency of much denser hydrocarbon fuels. Furthermore, the carbon produced in the reformation process can also be burned in the supersonic combustion chamber. Of course, to be practical, the net energy available from combustion of the hydrogen

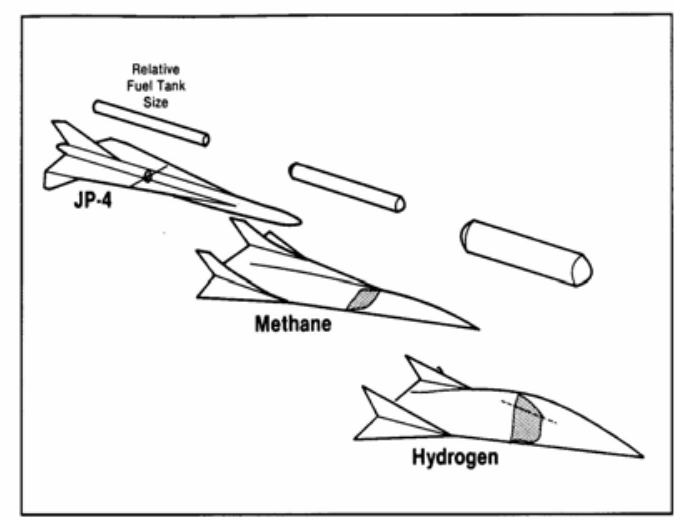

Fig. 1. Effect of fuel selection on hypersonic vehicle size. 


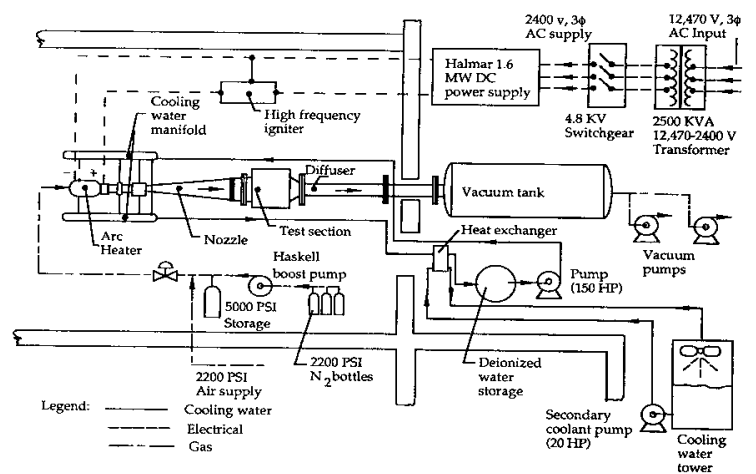

Fig. 2. Schematic of arc heater facility.

and carbon produced in the pyrolysis would have to be sufficient to offset the electrical energy required for the pyrolysis.

A preliminary feasibility study of the concept was presented by Lee et al. ${ }^{1}$ The purpose of the present study was to provide experimental validation of the feasibility of the pyrolysis concept, optimize design parameters such as specific power and voltage-to-current ratio, and experimentally determine the efficiency of the process.

\section{TEST FACILITY DESCRIPTION}

\section{$\underline{\text { Arc Heater Test Facility }}$}

A 1.6 MW DC electric arc heater facility was selected for conducting the experimental study. ${ }^{2}$ The arc heater (Thermal Dynamics Model F5000) utilizes a vortex-stabilized, high voltage, moderate pressure DC electric arc. A schematic

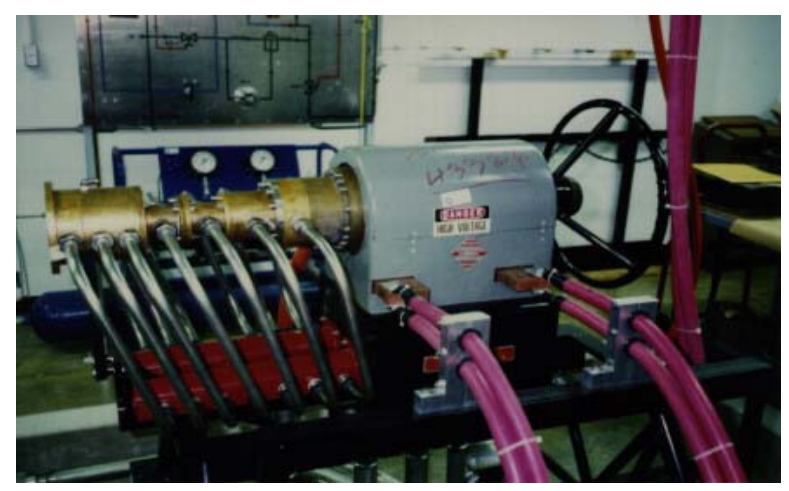

a. Photograph of Thermal Dynamics F-5000 arc heater
Fig. 3. Arc heater.

of the arc heater facility is shown in Fig. 2, and photographs of the heater are shown in Fig. 3. A detailed description of the facility, including operational characteristics, is given in Ref. 2. The performance map in the form of total pressure vs. total enthalpy for nitrogen as the test gas is shown in Fig. 4.

Gas is introduced into the arc chamber through tangential injection slots, thus forming an intense vortical flow that centers the arc column. The arc stretches from a tungsten cylinder at the base of the cathode barrel through the anode barrel and into the plenum chamber. The expansion of the gas into the plenum chamber reduces the strength of the vortex, thus allowing the arc to attach to the copper surface. However, sufficient residual vorticity is present to cause the arc attachment point to rotate, thus preventing attachment at a single location that might cause a burnthrough to the cooling water passages. For aerodynamic applications, nitrogen is used primarily as the working gas to prevent oxidizing the tungsten cathode. Oxygen can be added through injection ports in either the anode barrel or plenum chamber to create simulated air, if needed.

Originally, a high frequency igniter was used to step up the open circuit voltage to approximately $10 \mathrm{kV}$ to initiate breakdown. However, the electromagnetic noise generated by the igniter caused serious problems with sensors. Thus the igniter circuit is now bypassed and the arc heater is started with argon flow. The nominal $2650 \mathrm{~V}$ open circuit potential is sufficient to initiate breakdown of the argon, and

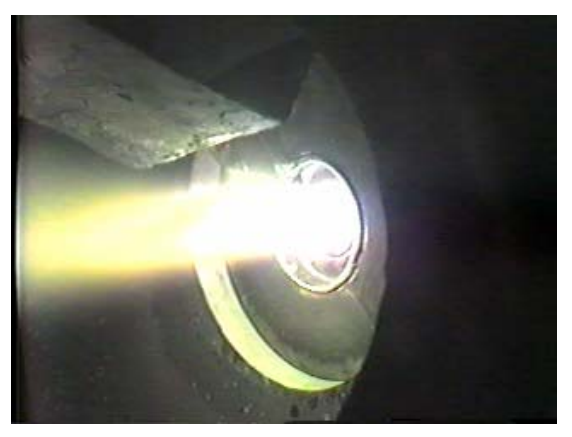

\section{b. Hot nitrogen exhausting into ambient air}

as soon as the arc is struck, the gas flow is rapidly switched to nitrogen. 

is

A representative operating point for nitrogen

$\begin{array}{ll}\text { Arc Current } & 550 \mathrm{~A} \\ \text { Arc Voltage } & 880 \mathrm{~V} \\ \text { Chamber Pressure } & 2.76 \mathrm{~atm} \\ \text { Nozzle Mass Flow } & 0.090 \mathrm{~kg} / \mathrm{s} \\ \text { Stagnation Enthalpy } & 4900 \mathrm{~kJ} / \mathrm{kg} \\ \text { GasPower } & 441.0 \mathrm{kWe}\end{array}$

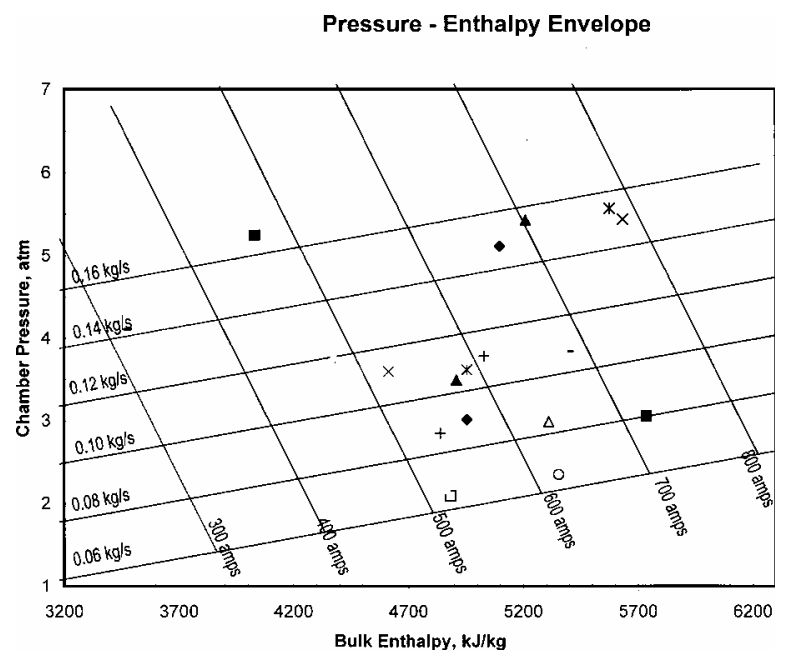

Fig. 4. Arc heater performance map with nitrogen.

Assuming no change in efficiency, the main difference between methane and nitrogen operation should be an increase in chamber pressure for methane. The ratio of the gas constant of nitrogen to methane is 1.75 , so for the same gas flow the pressure should be 1.75 times higher. Thus with the arc heater operating on methane, a first-order estimate of the chamber pressure is $4.8 \mathrm{~atm}$. Several modifications to the arc heater facility were required to switch from nitrogen to methane operation, and are summarized below.

\section{Gas Injection System}

Modifications to the gas injection system involved running additional plumbing lines from the remotely-located methane storage bottle, installation of the necessary control valves to allow starting the arc heater with argon, then switching to methane operation after arc initiation (typically 1-2 s), installation of flashback arrestors, recalibration of the flow metering noz- zle for methane operation, and installation of safety measures to minimize the possibility of methane leakage into the test area.

\section{Cooling Water System}

Additional pipe and fittings were installed in order to move the arc heater farther away from the existing test section to allow insertion of the new diagnostic chamber. Further, cooling lines were run from the arc heater cooling water manifolds to the diagnostic chamber, carbon trap and optical probe.

\section{Vacuum System}

The arc heater vacuum system was used to evacuate the air from the test chamber prior to a run to minimize the possibility of fire or explosion inside the chamber. A secondary function was safely disposing of the hydrogen and other flammable products of methane pyrolysis. An existing high capacity mechanical pump was used for initial evacuation of the test chamber. Under normal operation, the vacuum is sustained

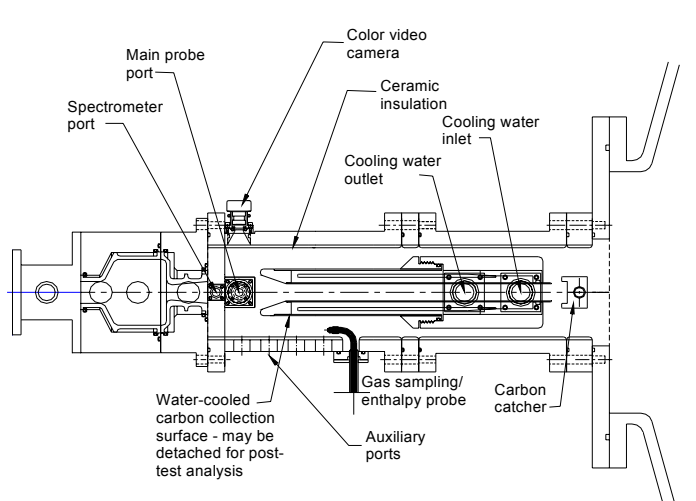

Fig. 5. Schematic of fuel reformation diagnostic chamber.

during a test run by an air ejector pump driven by high pressure air from the compressor plant.

\section{Diagnostic Chamber}

A diagnostic chamber was designed and fabricated to collect the exhaust products from the fuel reformation processes occurring in the arc heater. A schematic is shown in Fig. 5, and a photograph of the diagnostic chamber is shown in Fig. 6. A water-cooled cold trap is located at the center of the diagnostic chamber for collection of the carbon particles. This trap was designed with two removable sections, a hollow 
probe and a collection cup located at the base of the probe. These can be removed after a test run for weighing the carbon deposit. Gaseous species formed in the fuel reformation process, anticipated to be a mixture of $\mathrm{H}_{2}, \mathrm{CH}_{4}$, and trace amounts of various $\mathrm{CH}$ species, were sampled via emission spectroscopy. Two viewing ports were located at the entrance to the chamber for observing the spectra emitted from the arc heater exhaust plume.

\section{Diagnostic Instrumentation}

In addition to the normal arc heater instrumentation (described in Ref. 2) for determination of arc heater total pressure and enthalpy, an Ocean Optics USB2000 fiber optic spectrometer was used to examine the gas species. A web camera was also available for viewing the interior of the test section and arc chamber during actual runs.

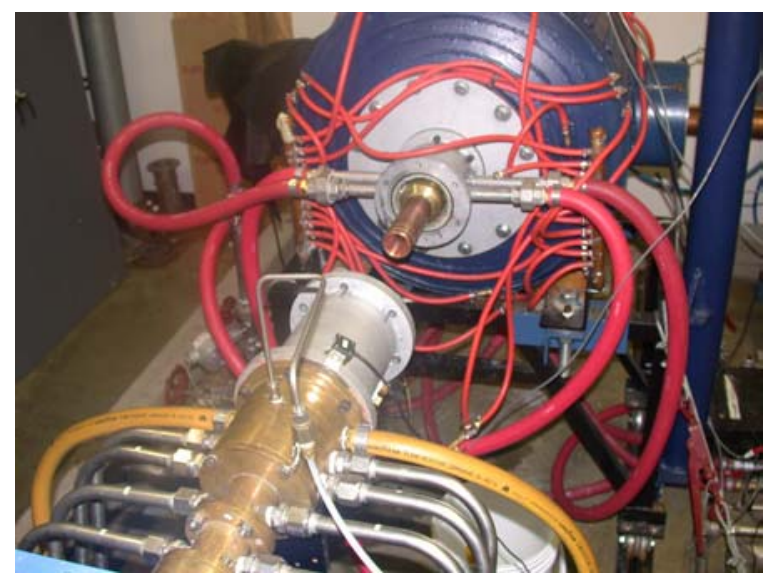

Fig. 6. Photograph of fuel reformation diagnostic chamber showing carbon cold trap.

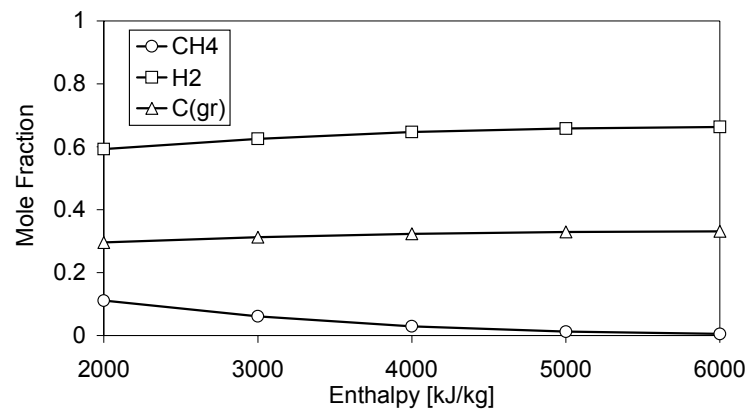

Fig. 7. Computed mole fractions for methane pyrolvsis as a function of total enthalnv at $3.5 \mathrm{~atm}$.

\section{ANALYTICAL PREDICTIONS}

Computed species concentrations using the NASA CEA code ${ }^{3}$ are shown in Figs. 7 and 8 for the anticipated range of test conditions. Figure 7 shows the effect of total enthalpy variation at a nominal total pressure of $3.5 \mathrm{~atm}$, whereas Fig. 8 shows the effect of pressure variation at a nominal total enthalpy of $4000 \mathrm{~kJ} / \mathrm{kg}$. Total enthalpy variation is seen to have a moderate effect on species concentration, whereas, the effect of pressure variation over the range of values shown is almost negligible. The temperature corresponding to the enthalpy variation shown in Fig. 7 ranges from 1000 to $1500 \mathrm{~K}$. These temperatures are much lower than those observed for nitrogen over the same enthalpy range (of the order of 4000 to $5000 \mathrm{~K}$ ). The much lower temperatures are due to the internal energy associated with dissociation of the methane.

\section{EXPERIMENTAL RESULTS}

\section{Initial Test Results from 1.6 MW Arc Heater}

The experimental test program commenced with shakedown testing of the arc heater with methane. However a failure occurred in the DC

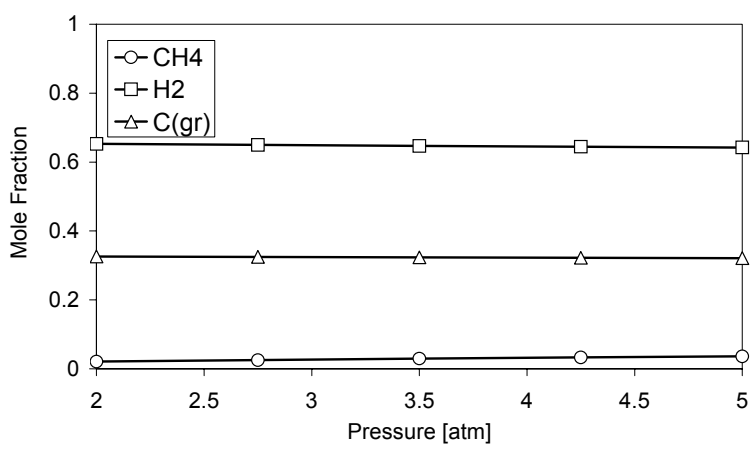

Fig. 8. Computed species concentration for methane pyrolysis as a function of total pressure at a total enthalpy of $4000 \mathrm{~kJ} / \mathrm{kg}$.

power supply after only one second of operation during the first test run. The nominal conditions for the first test run were $I=500 \mathrm{~A}, \dot{m}=0.11$ $\mathrm{kg} / \mathrm{s}, h_{t}=4500 \mathrm{~kJ} / \mathrm{kg}$, and $p_{t}=3.5 \mathrm{~atm}$, although the run duration was too short to obtain sufficient data for determining actual arc heater total enthalpy and pressure. The spectrometer was not installed for this test run; however as shown in Fig. 9, the carbon cold trap was totally covered with a very fine carbon powder deposit, clearly indicating that methane pyrolysis had occurred. 


\section{Installation of $5.6 \mathrm{~kW}$ Arc Torch}

In order to explore an alternative method for evaluating feasibility of the proposed methane pyrolysis concept, a small plasma cutting torch (Hypertherm Powermax 600) was installed. This torch is nominally rated at $5.6 \mathrm{~kW}$, with an operating voltage of 200-320 V, a variable current output of 20-40 A, and a flow rate of approximately $6 \mathrm{scfm}$. The torch control system was modified to allow remote operation, and a flange was fabricated to mount the plasma torch

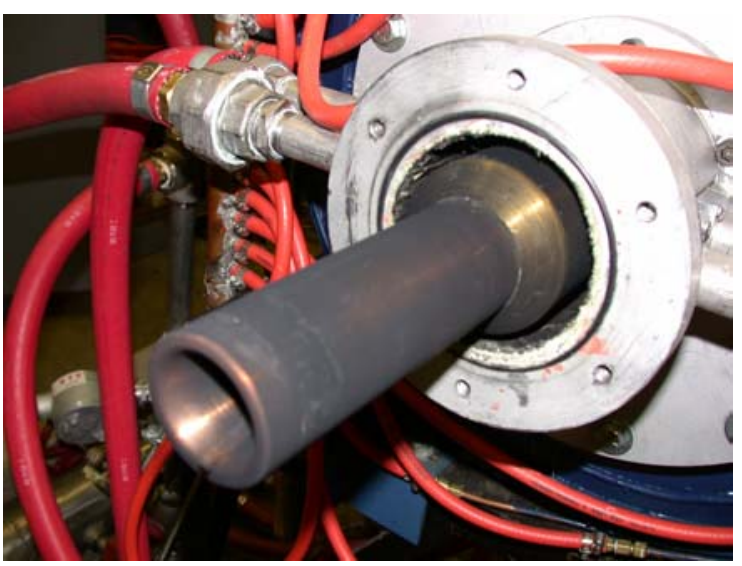

Fig. 9. Carbon deposition resulting from methane pyrolysis.

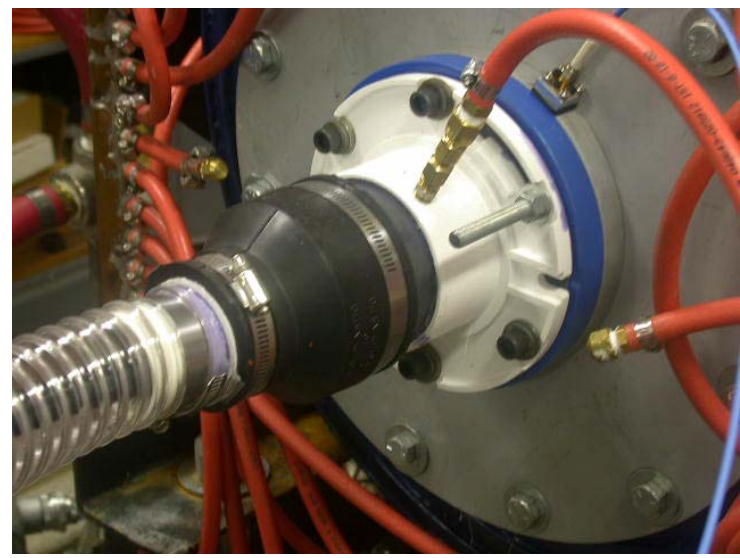

Fig. 10. Photograph of Hypertherm plasma torch installation.

directly to the fuel reformation diagnostic chamber (Fig. 10).

The torch has the capability of operating in a non-transferred arc mode. The main difficulty with this torch is that most of the gas flow bypasses the arc in order to provide electrode cooling and enhance arc jet confinement. The total gas flow is approximately $6 \mathrm{scfm}(170 \mathrm{l} / \mathrm{min})$, but the fraction of this which flows in proximity to the arc column is unknown. Further, some of the gas is also blown back through the torch handle, which does not present any problem when it is operated with nitrogen or air, but is dangerous when a combustible gas is used. In order to safely conduct the experiments, it was necessary to enclose the handle portion of the torch so that the combustible gas could be contained and vented outside. As an additional precaution, the torch handle enclosure also had a continuous flow of argon going into it. The gas control plumbing was taken out of the plasma torch power supply as an additional safety measure. Details of the installation are shown in Fig. 11.

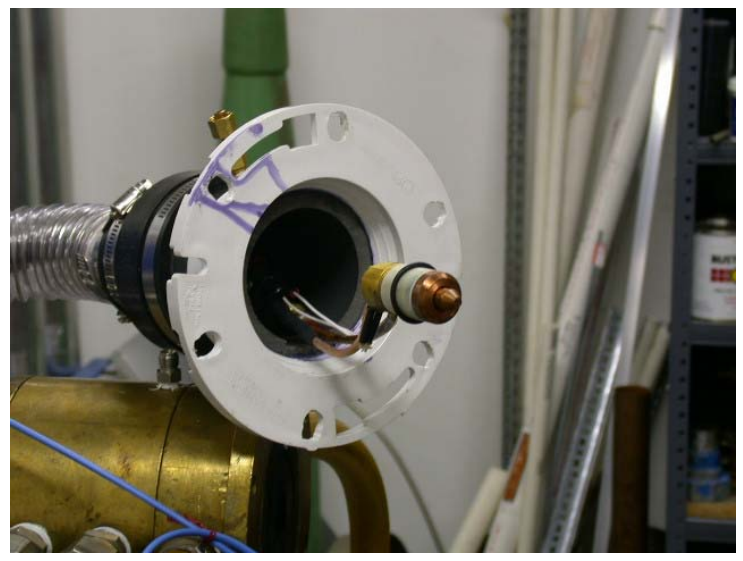

Fig. 11. Photograph of Hypertherm Plasma Torch showing modifications for methane operation.

The only instrument used for these tests was the emission spectrometer, which viewed the plume from the side through a port in a 3/4-in. thick spacer (the original use of the spacer was to adjust the distance of the carbon trap from the arc heater nozzle). Teflon tape was stretched over the end of the fiber optic cable in order to attenuate the light and prevent saturating the spectrometer. No cold surface to capture carbon was installed for these tests. Because the arc jet was discharging into a vacuum rather than onto an electrically conductive surface, the torch system was set to the non-transferred arc mode. This mode limits the current to approximately 12 A.

The small-scale test runs were each less than a second in duration, due to the torch tripping off due to low supply pressure. Unfortunately, 
the pressure could not be increased without causing a relief valve to open in the fuel gas system. However, although short, the test duration did prove to be sufficient to take $100 \mathrm{~ms}$ "snapshots" of the emission spectra of the arc plume.

\section{Test Results with $5.6 \mathrm{~kW}$ Arc Torch}

Several preliminary test runs were conducted with either nitrogen or hydrogen gas flowing through the torch to provide a base line of spectral emission data to aid in interpretation of the more complex emission spectra from the subsequent methane test runs. The spectral emission

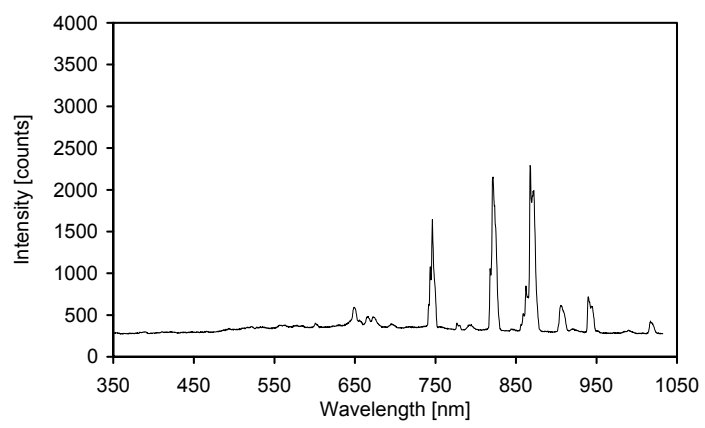

Fig. 12. Emission spectrum of nitrogen.

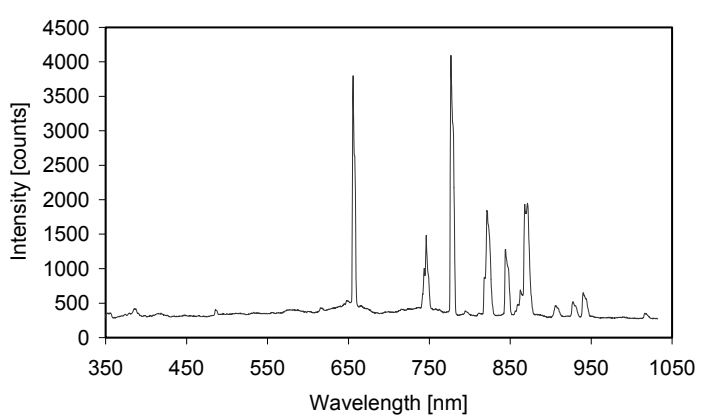

Fig. 13. Emission spectrum of hydrogen.

data from these runs are shown in Figs. 12 and 13.

Four tests were made for hydrogen. Repeatability was excellent and the dominant spike at a wavelength of $655.7 \mathrm{~nm}$ was identical to four significant digits for all four test runs. The spectral peaks were compared with data from the
NIST Atomic Spectra Database ${ }^{4}$ in Tables 1 and 2 . The first column lists the experimental wavelengths (nm), and the second, third and fourth columns are wavelengths for atomic species anticipated to be present in the arc heater exhaust plume that lie within $\pm 10 \mathrm{~nm}$ of the measured wavelength. The copper and hafnium data are included since these are the primary materials used in the plasma torch electrodes, and could be present in the exhaust stream as a result of electrode erosion. If blanks are shown in Tables 1 or 2 for any species, then the tabulated NIST data did not contain spectra within $\pm 10 \mathrm{~nm}$ of the

Table 1. Comparison of experimental spectral lines for nitrogen with published NIST data (nm)

\begin{tabular}{|cccc|}
\hline Data & N & Cu & Hf \\
\hline 649.5 & $\mathbf{6 4 8 . 8}$ & 648.4 & 655.7 \\
746.1 & 746.8 & 743.4 & $\mathbf{7 4 6 . 4}$ \\
821.5 & $\mathbf{8 2 1 . 6}$ & 827.8 & 820.5 \\
867.9 & $\mathbf{8 6 8 . 0}$ & 860.9 & 871.1 \\
905.6 & $\mathbf{9 0 6 . 0}$ & & 900.5 \\
939.6 & $\mathbf{9 3 9 . 6}$ & & \\
\hline
\end{tabular}

Table 2. Comparison of experimental spectral lines for hydrogen with published NIST data (nm)

\begin{tabular}{|cccc|}
\hline Data & H & Cu & Hf \\
\hline 655.7 & $\mathbf{6 5 6 . 3}$ & 655.1 & 655.7 \\
746.1 & & 740.4 & $\mathbf{7 4 6 . 4}$ \\
776.9 & & $\mathbf{7 7 7 . 9}$ & 775.8 \\
821.9 & & 827.8 & $\mathbf{8 2 4 . 9}$ \\
844.5 & & 850.3 & $\mathbf{8 4 6 . 0}$ \\
871.7 & & & $\mathbf{8 7 1 . 1}$ \\
941.7 & $\mathbf{9 5 4 . 6}$ & & \\
\hline
\end{tabular}

measured wavelength. The tabulated wavelengths shown in bold in Tables 1 and 2 were tentatively identified as the species most likely to be responsible for the spikes shown in Figs. 12 and 13. 


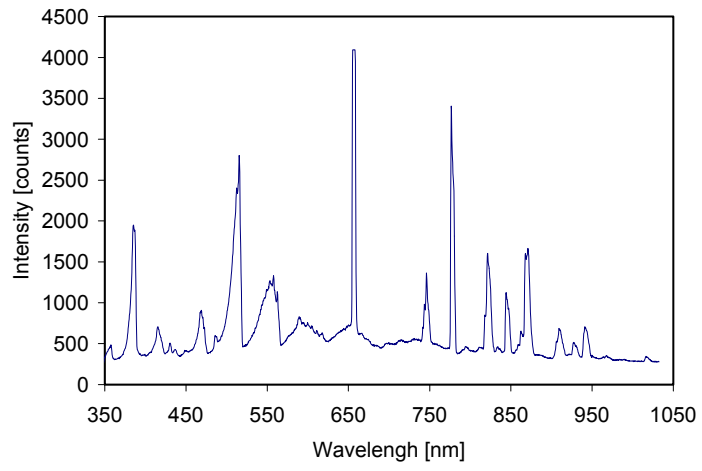

Fig. 14. Emission spectrum of methane (Run \#1).

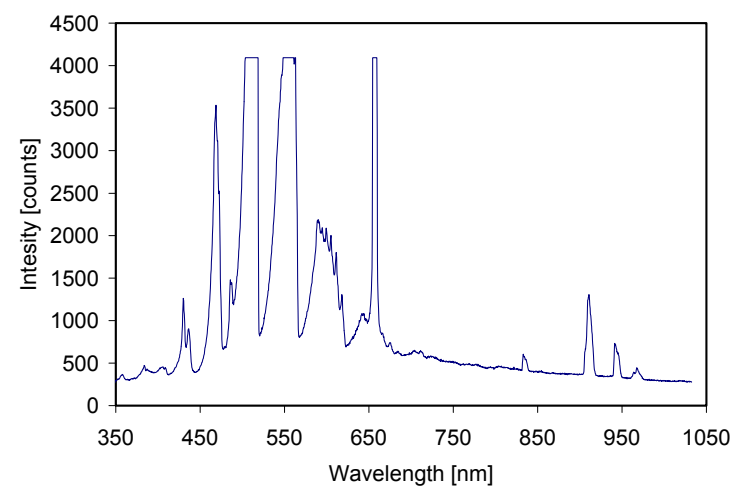

Fig. 15. Emission spectrum of methane (Run \# 2).

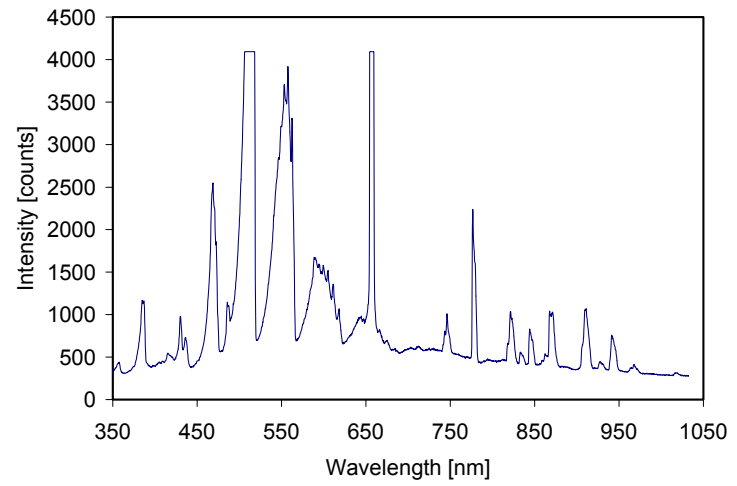

Fig. 16. Emission spectrum of methane (Run \# 3).

For the nitrogen test (Table 1), all of the observed spectral lines agree closely with NIST data. However, the $746.1 \mathrm{~nm}$ spectral line is thought to be due to hafnium $(746.4 \mathrm{~nm})$, since it also appears in the pure hydrogen test run (Table 2 ). The results presented in Table 2 for hydrogen show that only two of the wavelengths are most likely due to hydrogen emission. These are the 655.7 and $941.7 \mathrm{~nm}$ spectral lines; however it is noted that both copper and hafnium have emission lines that are also equally close to the 655.7 $\mathrm{nm} \mathrm{H}$ line. Since this spectral line is not observed in the pure nitrogen test, it is attributed to hydrogen. The other spectral lines appear to be due to either copper or hafnium. Note that neither copper nor hafnium has emission lines close to $941.7 \mathrm{~nm}$. The closest $\mathrm{H}$ line is $954.6 \mathrm{~nm}$; it is possible that the $941.7 \mathrm{~nm}$ wavelength is associated with some other transition. Thus far, however, we have not been able to identify a possible source, and thus are tentatively identifying that spectral line as hydrogen.

Three test runs were made with methane (emission spectra shown in Figs. 14-16), and data from all three runs are compared with data from the NIST database in Table 3 for the anticipated hydrogen, carbon, copper and hafnium atomic species. Note that all three methane runs show high intensity emission in the 655-659 nm range, which is close to the $655.7 \mathrm{~nm}$ spike observed in the pure hydrogen runs. The exact wavelength corresponding to peak emission could not be determined due to signal saturation. Note that this wavelength is also close to wavelengths emitted by copper and hafnium; however we believe that the emission is from hydrogen. There is no comparable line in the pure nitrogen test, which should be present if the emission came from either copper or hafnium excitation. Several of the high intensity emission peaks below the $655.7 \mathrm{~nm}$ line appear to be due to carbon emission, which is consistent with the observed carbon deposit downstream of the torch exhaust plane.

A search of the NIST molecular spectral database for hydrocarbons did not reveal any wavelengths in the range of the experimentally observed spectral emissions. Similarly, the data of Gale et al. ${ }^{5}$ for molecular hydrogen spectral emission do not show any wavelengths within the observed range for the hydrogen test. Thus we conclude that the measured wavelengths shown in Figs. 14-16 are from atomic transitions.

\section{CONCLUDING REMARKS}

The limited test results obtained from the one test run with the Thermal Dynamics arc heater conclusively demonstrated that the reformation 
Table 3. Comparison of experimental spectral lines for methane with published NIST data (nm).

\begin{tabular}{|ccccccc|}
\hline Data & Data & Data & H & C & Cu & Hf \\
(Run \# 1) & (Run \# 2) & (Run \# 3) & & & & \\
\hline 386.8 & & 386.8 & 383.6 & 387.6 & $\mathbf{3 8 6 . 4}$ & $\mathbf{3 8 7 . 2}$ \\
& 430.5 & 430.5 & 434.0 & $\mathbf{4 3 0 . 6}$ & 429.2 & $\mathbf{4 2 9 . 4}$ \\
469.2 & 468.8 & 468.8 & & 467.4 & $\mathbf{4 6 8 . 2}$ & $\mathbf{4 6 9 . 9}$ \\
515.7 & 515.7 & 515.7 & & $\mathbf{5 1 5 . 9}$ & $\mathbf{5 1 5 . 8}$ & $\mathbf{5 1 5 . 8}$ \\
557.5 & 557.5 & 557.5 & & 555.1 & $\mathbf{5 5 7 . 4}$ & $\mathbf{5 5 7 . 6}$ \\
591.1 & 591.1 & 591.1 & & 589.6 & $\mathbf{5 8 9 . 8}$ & 592.6 \\
$655.4-$ & $655.4-$ & $655.4-$ & & & & \\
658.1 & 659.5 & 659.5 & $\mathbf{6 5 6 . 3}$ & $\mathbf{6 5 7 . 8}$ & $\mathbf{6 5 7 . 7}$ & $\mathbf{6 5 5 . 7}$ \\
746.1 & & 746.1 & & 747.3 & 743.4 & $\mathbf{7 4 6 . 4}$ \\
776.6 & & 776.6 & & $\mathbf{7 7 7 . 2}$ & 777.9 & 775.8 \\
821.8 & & 821.8 & & 819.7 & 827.7 & $\mathbf{8 2 0 . 5}$ \\
844.2 & & 844.2 & & 840.9 & 850.3 & $\mathbf{8 4 6 . 0}$ \\
871.4 & & 871.4 & & 869.7 & & $\mathbf{8 7 1 . 1}$ \\
911.5 & 911.2 & & & $\mathbf{9 1 1 . 2}$ & & \\
942.0 & 942.0 & & $\mathbf{9 4 1 . 4}$ & & \\
\hline
\end{tabular}

process is viable, with substantial formation of pure carbon, as predicted from the CEA calculations. Further, the spectroscopic data obtained with the small plasma cutting torch provided further evidence that both hydrogen and carbon were produced in methane pyrolysis. Quantitative data regarding mole fractions could not be obtained in the limited time available.

We are currently modifying the Hypertherm torch installation to obtain the necessary data to quantify the thermal environment (total enthalpy and pressure and species concentrations) to permit quantitative comparisons with the NASA CEA code predictions.

\section{Acknowledgements}

The experimental investigation was supported by a grant from MSE, Inc. (Contract No. 03C671CR), under the direction of Dr. Y.M. Lee. This work was part of a NASA SBIR Grant NAS1-01007.

\section{REFERENCES}

${ }^{1}$ Lee, Y. M., Czysz, P., \& Bruno, C, "Implementation of Magnetohydrodynamic Energy Bypass Process for Hypersonic Vehicles - Status Report," NASA/MSFC/JPL/UAH $14^{\text {th }}$ Annual Advanced Space Propulsion Workshop, April 2003. 
${ }^{2}$ Boonjue, S.B., Roseberry, C.M. and Wilson, D.R., "Results from Initial Operation of a Continuous-Flow, Arc-Heated Hypersonic Propulsion Test Facility," AIAA Paper 96-4505, AIAA 7th International Spaceplanes and Hypersonic Systems and Technologies Conference, Norfolk, Virginia, November 18-22, 1996.

${ }^{3}$ Gordon S. and McBride B., "Computer Program for Calculation of Complex Chemical
Equilibrium Compositions and Applications, I. Analysis," NASA Reference Publication 1311, October 1994.

${ }^{4}$ NIST Atomic Spectra Database, http://physics.nist.gov.

${ }^{5}$ Gale, H.G., Monk, G.S. and Lee, K.O., "Measurements of Wave-Lengths in the Secondary Spectrum of Hydrogen ," The Astrophysical Journal, Vol. 67, No. 2, 1928, pp. 89-113. 